\title{
The Relevance of Statistics to Library Evaluation
}

\begin{abstract}
There has been increasing concern about standardizing library statistics. Yet conventional statistics are inner-directed and static measures. A library system should be evaluated in terms of function related to use, i.e. its efficiency and effectiveness. Several methods used in evaluation are examined. The concept of the library as a system is developed and an approach to evaluation is outlined. In conclusion this paper considers the relevance of statistics, and indicates briefly what types of data should be collected.
\end{abstract}

L systematically since the nineteenth century. Categories traditionally covered include sources of income; expenditure in terms of personnel, books, materials, and other expenses; size of collection; circulation; and type of personnel. There has been increasing concern about improving this type of data by establishing more exacting definitions. Yet these statistics have mainly focused on the internal aspects of the library and emphasize its more static characteristics. There is need for inquiry into the meaning of statistics, as they relate to evaluation of the library system, comparisons between systems, and developing overall concepts of library service. This paper proposes the formulation of statistical methods and standards which are more relevant to the goals and function of libraries.

Miss Salverson is Assistant Librarian in charge of Readers' Services in Jefferson Community College, Watertown, New York.
Statistics are quantitative measurements of stated facts or processes. The meaningfulness of a statistic depends on the purpose for its use, the significance of that purpose, the relevance of the statistic, the accuracy of compilation, and the interpretation. Statistics are used to give a concise and objective representation of facts. They provide a simplified summary of complex data, for ease of comprehension and objectivity. They can be used for cross-comparison. Statistics are necessarily an oversimplified description of facts, however, and should be thus interpreted. It is highly important in statistical analysis that the elements to be quantified be selected carefully, to provide a truly representative statistical schema. ${ }^{1}$

Library statistics are compiled for various purposes-record keeping, supportive material for influencing management, reporting to national agencies, indication of individual progress, and to provide

1 "Numerical News" (editorial), Library Journal, XCI (May 1, 1966), 2288. 
objective means for comparing libraries. This paper is concerned with the relevance of statistics to the purpose of evaluating libraries. The validity of a measurement depends on the purpose. "It is important, therefore, to avoid complacency because standard measures will soon be agreed upon, when in reality such measures have no real meaning in relation to our objectives." ${ }^{2}$ For example, the number of items circulated in a year is useful for a permanent record of circulation. If the circulation increases greatly, it may be taken as a general indication of expanded activity, and vice versa. Circulation figures are weak criteria of the library's use. Library patrons also read books in the library,' obtain information by telephone and from the reference librarian.

Evaluation is intrinsic to the library field. It is necessary in assessing the needs for library service, in appraising the library operation, and in weighing resources so as to give insight into the significance of libraries; it is necessary for purposes of improving library practices, and to aid in the formulation of objectives. Some librarians are opposed to the use of statistics as being largely inadequate for library evaluation. They feel that the quality of library service cannot be represented by numbers; others have proposed mathematical formulas for assessing a library. These positions must be considered. It is evident that some sorts of criteria are needed for evaluation, comparison, and establishment of principles.

\section{Subjective Evaluation}

Evaluation of a library by subjective means has the advantage of permitting a view of the system as a whole in terms of its objectives, of allowing consideration of all aspects of operations and

\footnotetext{
${ }^{2}$ James Krikelas, "Library Statistics and the Measurement of Library Services," ALA Bulletin, LX (May 1966), 498.
}

subtle distinctions involved in quality of service. It requires extreme perceptiveness by the librarian, as well as detachment from daily routines. Also, it is only possible where the librarian has close contact with all staff and operations. Thus this method can be useful only in the smaller libraries. It can, however, also result in a biased estimation on the part of the librarian. He may think the library is "successful," when actually many patrons have ceased coming because of lack of information, or other such unrecognized factors. Furthermore, few libraries can continue to operate in isolation, and those which do are not a benefit to the field. Such a library's activity and progress can only be stated in subjective terms. This does not provide objective verification for the librarian's findings and does not easily lend itself to comparison by others.

\section{Mathematical Formula}

Evaluation by a well based mathematical formula might provide verifiable results in an objective form. It would rate the library on a quantified scale, and would be useful to other libraries for comparisons. Beasley ${ }^{3}$ suggested the following measure:

$$
\begin{aligned}
& \frac{\mathrm{B}}{\mathrm{P}}=\sqrt{\frac{\mathrm{C}}{\mathrm{P}}} \cdot \mathrm{S} \\
& \frac{\mathrm{B}}{\mathrm{P}}=\text { books per capita }
\end{aligned}
$$

Where:

$$
\begin{gathered}
\mathrm{B}=\text { books (resources) } \\
\mathrm{C}=\begin{array}{c}
\text { measure of users (broader than } \\
\text { circulation) }
\end{array}
\end{gathered}
$$

\footnotetext{
${ }^{3}$ From a presentation by Kenneth E. Beasley, director of the Kansas Legislative Council, and a member of the faculty, Department of Political Science at the University of Texas, at the Conference on "Measurement and Evaluation in Library Research," September 10-13, 1967, Champaign, Illinois. Described in a memorandum from Mary D. Quint to Robert W. Levesque, Syracuse University Research Corporation,
} September 28, 1967. 
$\mathrm{P}=$ population

$\mathrm{S}=$ research/study factor (determined by another ratio of physical facilities, non-fiction, periodicals, personnel, hours of service)

The original model is more detailed. ${ }^{4}$ Extended criticism could be made of this formula. It could be said that the number of books to be provided per person is inadequate as a formula for "measurement of library service." 5 This does not indicate how well all the services are functioning to bring the user in contact with needed information. It does not consider quality of the collection, but assumes that there is a "positive correlation between quantity and quality." 6 "There is, however, no known evidence to demonstrate that size is correlated to quality or service in any way." ${ }^{\prime}$ Further, the $\sqrt{ }$ was used because circulation is less significant as it increases. Assuming this to be true, why not use ${ }^{3} V^{-}$or $\sqrt[4]{ }$ ? Each of these would likewise indicate that circulation has less influence as it increases. It seems to be a rather arbitrary operation. It is difficult to assess critically this formula without more knowledge of how Beasley would support it. However, it is being used here as an example of how completely quantitative formulas are greatly inadequate for evaluating the complexity of a library situation. They tend to be poorly founded in principle, do not take all variables into account, and are unsophisticated in design and mathematical operations. The result is not a meaningful assessment of library service.

\section{Conventional Library Statistics}

Conventional library statistics are largely inadequate for measuring the

${ }^{4}$ Ibid.

${ }^{5}$ Ibid.

- Ibid.

${ }^{7}$ Krikelas, op. cit., 497. system, since they are static and innerdirected. The library as a system should be measured in terms of function related to use. Expense is measured in terms of budget categories, yet it does not relate costs to time, space, and other variables. The collection is measured in number of volumes, often divided by form of material. This count is some indication of potential of the collection for providing service, but it does not show quality, subject distribution, and how much it is used. The figures could be related to those for circulation, but it at best would give only a crude estimate of use. The circulation statistic has been discussed previously. Statistics for type of personnel describe them as professional or clerical without relation to their activities. The standard statistics do not measure many aspects of library service, such as in-house use of materials, how many people actually come to the library, the ways in which patrons seek information, and the role of the reference staff.

\section{Use Studies}

Emphasis in recent years has been shifting toward learning the aspects of library use-how many users, their characteristics and needs. There have been a great number of use studies, often duplicative, using non-standardized methodologies. Often sampling techniques and data gathering are poorly conceived. Comparison of studies is difficult. Some use studies have tended to focus on the expressed desires and opinions of the patrons without integration with the system objectives. The studies to date have been generally unsophisticated in experimental design; also, few libraries have undertaken this type of analysis. Some statistics that are of real value in assessing library activities and clientele have been obtained by these methods. For example, Behling, at Ohio State University, used a questionnaire to ascertain 
who was using what facilities in the library on a particular day. It was found that nearly 55 per cent of the persons completing the questionnaire were using the library only for study. ${ }^{8}$ This sort of statistic has important implications for the particular library, and it should also encourage other librarians to consider such assessment.

\section{Systems Analysis}

Systems analysis is another method of evaluation which is receiving more attention in the literature. "One wonders why systems analysis techniques, so helpful in developing information systems themselves, are not applied to the development of tools for evaluating these systems." Most studies of systems at present are undertaken largely in connection with advanced techniques of information retrieval and dissemination. This includes a great number of relevance assessments, which center on one aspect of a specialized system. Studies have taken place largely on an individualized basis, without standardized methods. They may not be based on the system objectives. Only a limited number of studies have focused on the problems of the conventional library system. For example, some studies have been made of work flow in technical processing. At this point, it is desirable to look at the library as a system.

\section{The Library System}

A library provides access to information for a group of users. The system concept implies an organization of facilities, resources, and personnel in a design which implements the institutional

\footnotetext{
${ }^{8}$ Orlando Behling and Kermit Cudd, "A Library Looks at Itself," CRL, XXVIII (November 1967), 416-22.

Alan M. Rees, "Evaluation of Information Systems and Services," Annual Review of Information Science and Technology, II (1967), 8.
}

objectives. Library service is a process; as such it should be dynamic and flexible, adapting to the need for change. Prior to the establishment of the library, and contributing to its reason for existence, there are two elements: a group of people with a need for information and the information. There is a barrier between the two, i.e., the people who need something cannot get what they need. The librarian surmounts this interface by providing an approach for the user and bringing the information to him. The broad function is shown in the first diagram.

The librarian must define the user population, its characteristics, and needs, in order to select from the broad category of information those materials which are most relevant. He must organize these materials and provide channels of access. Means should also exist for the use of materials beyond the library collection. A librarian does not have direct knowledge of why a reader desires information, what he does with it, or how it affects him. The librarian has contact with materials and with users making requests. Yet, for efficient operation the library needs feedback from outside its domain.

The organization is managed by administrators. The remainder of the staff can be roughly divided into technical services (from selection of material through preparation) and readers' services (circulation and reference). Processes are coordinated within departments, and ultimately are directed toward service, as shown in the second diagram.

The collection (and availability of outside resources) is central to the internal workings of the library. Its materials, arrangement, and indexing are provided by the technical services; direct access is provided through readers' services. The collection should be dynamic, expanding, shifting in emphasis, and decreas- 


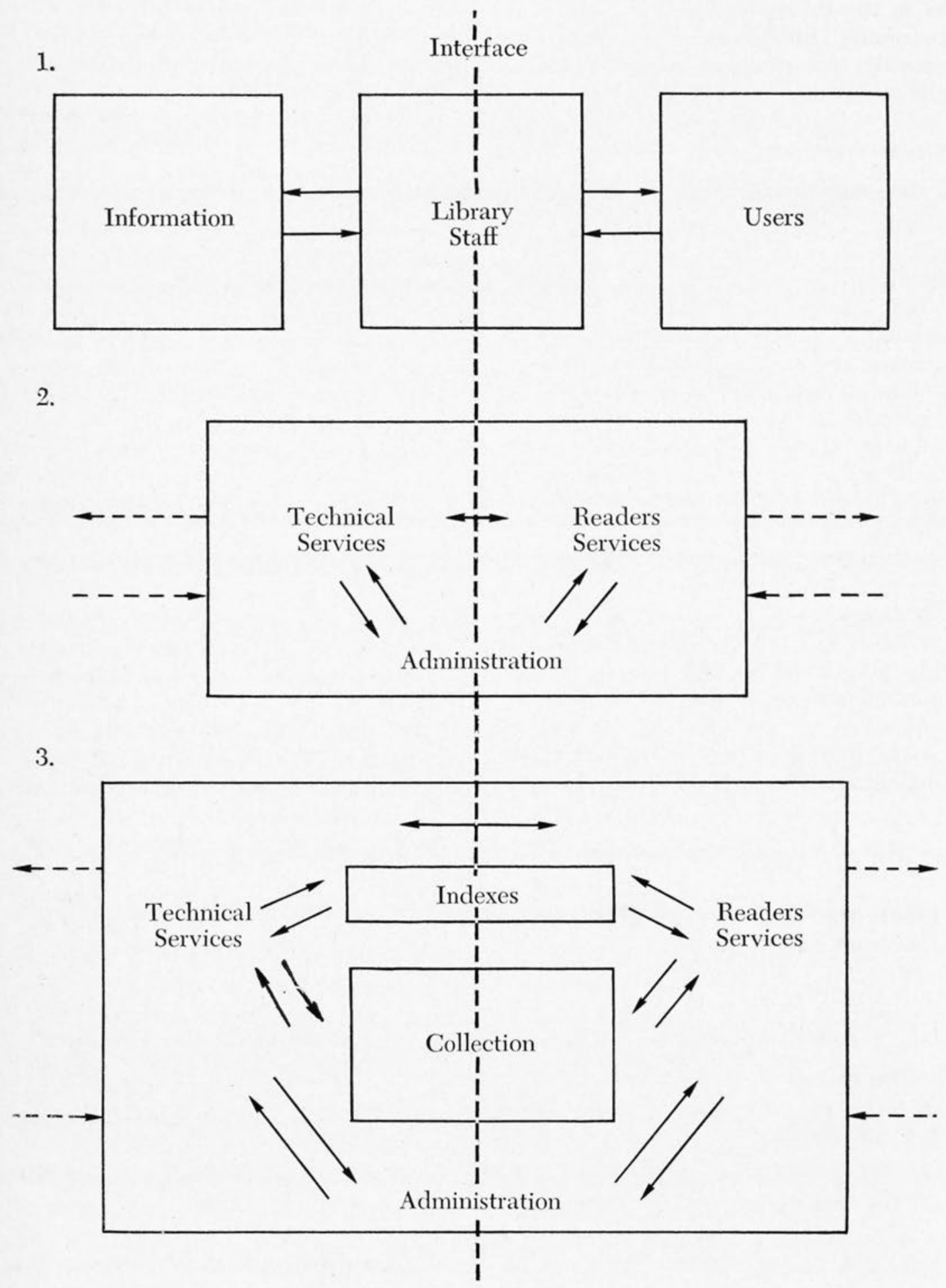


ing in some areas, according to demand, as in the third diagram. The schema is becoming increasingly complex. This provides for some conceptualization of the problem of evaluating.

\section{Criteria for Evaluation}

In evaluating the library we must consider the efficiency of its internal operation and its effectiveness in implementing the goal of service to users. ${ }^{10}$ These two criteria are necessarily interrelated. A library is established on the basis of a service objective. The organization of physical facilities, resources, and staff provides a means for the fulfillment of this objective in practice. Both aspects are important in maximizing the potential of the library. An inefficient library creates a waste of energy and cost; even though it may be useroriented, the possible extent of service is necessarily decreased. Likewise, a library which is ineffective in serving users may function smoothly and efficiently, but the continuation of such a system has little value.

The most basic formula for determining efficiency of an operation is:

$$
E=\frac{O}{I} \quad \text { efficiency }=\frac{\text { output }}{\text { input }}
$$

Lipetz translated this into terms useful for communication systems. ${ }^{11}$

$$
\mathrm{E}=\frac{\text { useful results (services) }}{\text { costs involved }}
$$

The cost factor includes expenditures in terms of materials, supplies, personnel, and equipment. If the cost is re-

\footnotetext{
${ }^{10}$ This distinction was made clear by Karen Breeding, a student at Syracuse University School of Library Science, in a preliminary draft paper on $R e$ search Libraries and a National Information Network, May 1968.

${ }^{11}$ Ben-Ami Lipetz, "The Evaluation of Communication Systems: Some Thoughts on Effectiveness," Sci-tech News (Winter 1966), 110-13.
}

duced, for example, by shortening the time required to catalog a book, efficiency is increased. There are many variables involved; considerations of time, space, and motion affect cost in various complex library operations. Thus a determination of the cost factor cannot be arrived at by means of a simple formula. We can change one small variable, however, keeping others constant, and then observe whether expenditures have decreased over a period of time.

The service factor is less tangible. It includes all products of the library operation which can be useful to patrons: reference service, cataloging and indexing, classification, preparation of bibliographies, the book collection, circulation. If these results are improved or increased, the efficiency ratio increases. This area is also subject to many variables, but, in addition, it is less quantifiable. For example, if we expand the collection, we may improve the services offered; however, this requires a qualitative judgment of what makes better services.

The interrelation between these two variables is not always considered by library planners. In the past there was extreme conservatism about expanding services; emphasis was placed on cost. Now there is a more general availability of funds and much emphasis on research in developing new technologies for improved service. There is a tendency to think that an innovation is justified if it can provide more sophisticated service, e.g., selective dissemination of information, computerized file search, or longdistance xerography. The practical importance of the cost factor is often neglected.

The efficiency ratio is suggested only as a guideline for aid in evaluation. It cannot be quantified as a simple percentage; methods at present are too unsophisticated for the defining of significant data, compiling, quantifying re- 
sults, determining of mathematical relationships, and assigning of constants. Thus there is an indication that we may be able to analyze statistically more in future than at present. The ratio is directly concerned with certain qualitative evaluations, however, such as the judgment of the value of a collection, which cannot be wholly quantified without losing our perspective.

The ratio implies that a resulting percentage will be less than ideal. In a system we do not seek to achieve perfection, but a workable organization. We must determine what degree of evaluation is desirable in terms of improved service. This must be seen as a longrange and cooperative investment also. A detailed evaluation by a few libraries can benefit a great number of others. The latter can eventually learn from the experience of the former, without as great an expenditure.

According to Lipetz ${ }^{12}$ the ratio of $\mathrm{O} / \mathrm{I}$ consists of unknowns: an infinite variety of factors may be substituted. It only assumes meaning in the context of the library's objectives. What is the library attempting to achieve? Are its aims valid? Then we must consider existing operations or new planning in relation to how the institutional goals can best be implemented, in terms of both cost and service.

If a library provides a high type of services (defined in terms of its objectives) at a low cost, it has a high efficiency. Although this is a desirable standard, it is not sufficient, since it does not indicate how or to what extent the library is, in effect, serving users. The criterion of effectiveness must also be applied. We must determine the relationship between level of service offered and actual use. The goal is that the expressed institutional objectives be implemented in practice.

$$
{ }^{12} \text { Ibid. }
$$

As stated previously, there is a great emphasis at present on improved services, and all types of libraries are gaining access to federal funds. As a result librarians may stress the need for acquiring new books, facilities, or personnel without considering the total cost in relation to how much this will increase actual use. Thus, a costly change which only moderately increases the use of the system is not worthwhile. It is evident that the elements involved in assessment of services are necessarily complex.

At this point it is interesting to consider the criteria of efficiency and effectiveness in relation to Daniel Gore's article, "The Mismanagement of College Libraries." ${ }^{13} \mathrm{Mr}$. Gore stresses his belief that libraries exist to provide books for readers, but that our college libraries do not provide the number of books needed for good service. Meanwhile, he claims, a great deal of money is being spent on librarians performing much clerical work. He maintains that by keeping funds constant, we can replace many professional personnel with less expensive clerical help, further reduce expense by instructing students in use of the library, and use the increased funds made available for the purchase of books. All this is accomplished "without sacrificing anything of value."14 In our formula of efficiency Mr. Gore has kept expense constant; therefore, we must consider services. The student has been instructed in the use of the library: this has "virtually eliminated the need for the ... services of a reference librarian."15 The service factor has been improved by making instruction available to students, but it has also been limited by omitting a regular reference librarian. Let us assume, as apparently Mr. Gore does, that these two changes in variables balance

\footnotetext{
${ }^{13}$ Daniel Gore, "The Mismanagement of College Libraries," AAUP Bulletin (Spring 1966), 46-51.

14 Ibid., 51.

15 Ibid., 47.
} 
each other out, and the service factor remains constant. Also, the book collection is being rapidly expanded; this will then increase the service factor and result in a more efficient system.

Now let us apply the effectiveness criterion. The increased efficiency has resulted from an increase in the number of books, but how effective is the resulting situation? To quote from "Guidelines for quality in college libraries": ${ }^{16}$

However, the presence of a supportive collection is, in itself, not enough. The degree to which faculty and students use the library as a means of extending their cultural frontiers is very definitely one measure of the calibre of the instruction that takes place on campus, as well as an indication of the amount of emphasis the administration places on intellectual matters. (italics added here)

What indications are there that the expanded collection has proved more useful to the student? Further, it is doubtful that a student can master the use of the library to the extent that he does not need reference assistance through a single course in bibliography. At present, it is indicated that even one year of fulltime study for librarians may be insufficient preparation for understanding the many and complex approaches to finding information (granted that much of this training has other objectives, e.g., administration). It is possible that the larger quantity of books has had little benefit and that the curtailing of reader assistance has greatly minimized the effect of the library on education. If this is true, then Mr. Gore's measure of effectiveness has decreased. Or, perhaps the effectiveness has remained the same; i.e., the students have learned to do on their own all that they needed help for previously from the reference librarian. If such a low level of reference assistance is required in practice, it would ap-

\footnotetext{
${ }^{16}$ New York State Education Department, "Guidelines for Quality in College Libraries," (Mimeo), 5 p.
}

pear that the educational goal of "selfeducation after college, and during it as well"17 is far from being effectively implemented.

\section{Statistics and Evaluation}

Evaluation of a system should be based on the scientific method. First, we must determine what the object of the system is; this has been discussed here in the most general way as service to users, but this must be better delimited in terms of explicit objectives. Next, data must be gathered on the functioning of the system and its actual benefit to the users. One could recommend here the methods of systems analysis for internal library operations and the use study for obtaining data on the population. Statistics are to be used insofar as data are measurable or would be useful in quantitative form. Statistical analysis is a tool for quantifying and classifying certain facts. Both selection of the particular elements of the system to be analyzed and statement of the relationship between these elements are judgments which must be determined by the librarian. This relates to the purpose of the system. "After the librarian makes this decision, statistical analysis can be used to evaluate the most likely values of various constants."18 Work in this area is largely unsophisticated at present. Therefore, it is best to begin with the most simple application of statistics. They should be used to the extent that is presently feasible, along with nonquantified information. In the final interpretation of a study the librarian will attempt to integrate the statistical data compiled with general considerations of other factors, and relate these to the initially stated objectives.

\footnotetext{
${ }^{17}$ Daniel Gore, op. cit., 50.

${ }^{18}$ Marianne Cooper and Herbert W. Cooper, "Interpreting Results of Statistical Studies," CRL, XXVIII (July 1967), 266.
} 
For controlled analysis of an existing system, it is advisable to concentrate on single aspects in relation to the whole. If we were to analyze the procedures involved in cataloging a book, and somehow shortened this operation, we could observe what effect this had on general efficiency, since other factors have been generally kept constant. As more knowledge of library systems is developed and methods are standardized, evaluation should become a regular part of system procedure.

The methods of systems analysis will be used to study routine technical services operations, considering time, output, cost, space, skill of personnel, physical facilities, and organization. This would make use of work-flow charts and flowprocess charts. Statistics would be compiled in conjunction with this on factors determined to be significant, e.g., cost of cataloging a book, time required to verify a title, how frequently a worker must resort to a certain cataloging tool. Similar analysis can be used for studying the users and reference service. Steps required to perform searches will be diagrammed and compared. Time and motion studies can be made for reference staff and users. A study was made at Wayne State University School of Medicine library "to determine the flow pattern in the use" of the library for planning of physical facilities. Locations occupied were noted and the amount of time spent there. ${ }^{19}$ Questionnaires and other techniques can also be utilized to gain information on user activities. Reference requests can be noted and classified. Again, selected statistical analyses could be made for such factors as number of users, classified by group, by facilities used, or by intent; number of re-

${ }^{19}$ Saul Herner and Mary Herner, "Information Needs and Uses in Science and Technology," Annual Review of Information Science and Technology, II (1967), 13-14. quests for extensive bibliographies; and so forth.

There is a need for standardization of statistics useful for system evaluation. Conventional cumulated statistics are not directly relevant to effective library service. The recent handbook published by American Library Association recommends that circulation figures for college and university libraries not be reported nationally-they represent only a segment of library use, and involve so many local variables, that they are useless for national comparison..$^{20}$ It might further be suggested that standard methodologies and type of data be developed so that libraries can be compared to some degree in actual use. In addition, sound criteria for technical services and readers' services are needed. Many aspects of library operation, notably building of the collection and provision of reference service, cannot be completely quantified. Library service is affected by a complexity of factors, and also judgments of value are necessary. If relevant objective system data can be provided to some extent, then other librarians can relate this to their own services, and make their own interpretations.

Society is now changing dramatically as a result of population expansion, volume and diversity of information needed by it, increased interdependence of functions, and improved technology in communications, types of media, and electronic data processing. Librarianship needs to be reevaluated in terms of these changes, so that libraries can effectively serve the population. This requires revision of principles in the profession. Fundamental principles must be based on a broad range of data from the field. The data available at present are of little use in interpretation, since measures

\footnotetext{
${ }^{20}$ American Library Association, Statistics Coordinating Project, Library Statistics: a Handbook of Concepts, Definitions and Terminology (Chicago: American Library Association, 1966), p. 22.
} 
of income, expenditures, collections, to them. The field at present needs much staff, and number of borrowers have lit- more relevant and better coordinated tle relevance to how libraries are func- statistical data.

tioning or what patrons do in relation

\section{ERRATUM}

In the article by Richard W. Trueswell entitled "User Circulation Satisfaction vs. Size of Holdings at Three Academic Libraries" in the May issue part of the key to Figure 5, page 210, was inadvertently omitted. Symbols shown on the graph relate as follows to the institutions listed:

- Mount Holyoke

$\odot$ Goodell (U. Mass.)

$\otimes$ Deering (Northwestern) 